\title{
UV Total Dose Nonvolatile Sensor Using Silicon-Oxide-Nitride-Oxide-Silicon Capacitor with Oxy-nitride as Charge-trapping Layer
}

\author{
Fuh-Cheng Jong, ${ }^{1}$ Wen-Ching Hsieh, ${ }^{2 *}$ Hao-Tien Daniel Lee, ${ }^{3}$ and Shich-Chuan $\mathrm{Wu}^{4}$ \\ ${ }^{1}$ Electronic Engineering Department, Southern Taiwan University of Science and Technology, \\ 1, Nan-Tai Street, Yungkang District, Tainan 710, Taiwan \\ ${ }^{2}$ Department of Opto-Electronic System Engineering, Minghsin University of Science and Technology, \\ Xinxing Road 1, Xinfeng 30401, Taiwan \\ ${ }^{3}$ Treasure Giant Technology Inc. 3F-1, 42, Lyushuei Road, Hsinchu City 30068, Taiwan \\ ${ }^{4}$ National Nano Device Laboratories, No. 26, Prosperity Road 1, Hsinchu Science Park, Hsinchu 30078, Taiwan
}

(Received May 2, 2017; accepted April 12, 2018)

Keywords: UV, sensor, SONOS, MOS, radiation

Silicon-oxide-nitride-oxide-silicon (SONOS) capacitor devices with an oxy-nitride as the charge-trapping layer (O-SONOS) could be candidates for UV total dose (TD) nonvolatile sensors. UV radiation induces a significant increase in the threshold voltage $V_{T}$ of the O-SONOS UV TD nonvolatile radiation sensors. The experimental results indicate that the UV-induced increase in $V_{T}$ for the O-SONOS capacitor device under positive gate bias stress (PGBS) is nearly $2 \mathrm{~V}$ after $100 \mathrm{~mW} \cdot \mathrm{s} / \mathrm{cm}^{2}$ TD UV radiation. The change in $V_{T}$ for the O-SONOS capacitor after UV irradiation is also correlated with UV TD up to $100 \mathrm{~mW} \cdot \mathrm{s} / \mathrm{cm}^{2}$ irradiation. The charge-retention loss of the nonvolatile O-SONOS capacitor after a 10-year retention is below $10 \%$. The UV TD information can be permanently stored and accumulated in nonvolatile O-SONOS capacitor devices. The O-SONOS capacitor device used in this study has demonstrated the feasibility of nonvolatile UV TD sensing.

\section{Introduction}

The measurement of UV irradiation total dose (TD) is very important in various UV radiation applications, such as biotechnology and medical technology. Semiconductor dosimeters offer many advantages. The dose sensing areas of semiconductor dosimeters are very small, and their dose sensitivity can be high in a small constrained space. A silicon-oxide-nitride-oxide-silicon (SONOS) capacitor device has been shown to be suitable for nonvolatile UV irradiation TD sensor applications. ${ }^{(1-3)}$ UV irradiation induces a significant increase in the threshold voltage $V_{T}$ of the SONOS capacitor device and this UV-induced increase in $V_{T}$ for the SONOS capacitor is correlated with UV TD. The reliability characteristic of $V_{T}$ retention for the SONOS capacitor device is good, even after a 10-year retention. The UV TD information can be stored and accumulated in this nonvolatile SONOS capacitor device permanently. ${ }^{(1-6)}$

*Corresponding author: e-mail: wchsieh@must.edu.tw https://dx.doi.org/10.18494/SAM.2018.1904 
For UV TD data writing, UV irradiation together with positive gate bias stress (PGBS) was impinged simultaneously on the SONOS capacitor device. Electrons from the valence band of the Si substrate can be excited by UV photons and the UV irradiation induces ionized electron-hole pairs in the silicon substrate of the SONOS capacitor device. The survival yield of the electron-hole pairs (escape from the recombination after UV radiation excitation in the substrate) depends on the electric field under PGBS. ${ }^{(7,8)}$ Under PGBS, negative charges are injected from the substrate into the charge-trapping layer and trapped in the charge-trapping layer of the nonvolatile SONOS capacitor device. The build-up of negative charge changes the threshold voltage $V_{T}$, and the $V_{T}$ shift depends on the absorbed TD of the UV irradiation. Electrons find it difficult to escape to the control gate owing to the relatively large barrier height of the thick $\mathrm{SiO}_{2}$ blocking oxide. As a result, negative charges are accumulated permanently in the trapping layers of the SONOS capacitor device. This is the UV-radiation-induced charging process in the nonvolatile SONOS capacitor device.

However, the improvement of the UV-radiation-induced charging effect and the charge-retention reliability characterization of a SONOS device after UV irradiation have not been well studied; they are discussed in this study. A SONOS device with oxynitride as the charge-trapping layer (O-SONOS) was proposed in this study. The UVradiation-induced charging effect and the charge-retention reliability of the O-SONOS devices were significantly improved. The electrical characteristics of the O-SONOS devices under various UV TD conditions, including radiation-induced charge effect, gate leakage current, and charge-retention reliability, are the main subjects of this study. Figure 1 shows the cross-sectional view of the SONOS devices. Figure 2 shows the charge generation and trapping states of the gate dielectric in the O-SONOS capacitor device after UV irradiation.

\section{Experimental Details}

The O-SONOS devices are prepared by adjusting the $\mathrm{Si}-\mathrm{O}-\mathrm{N}$ composition ratio during the nitride deposition of the SONOS capacitor for this study. SONOS capacitor structures were

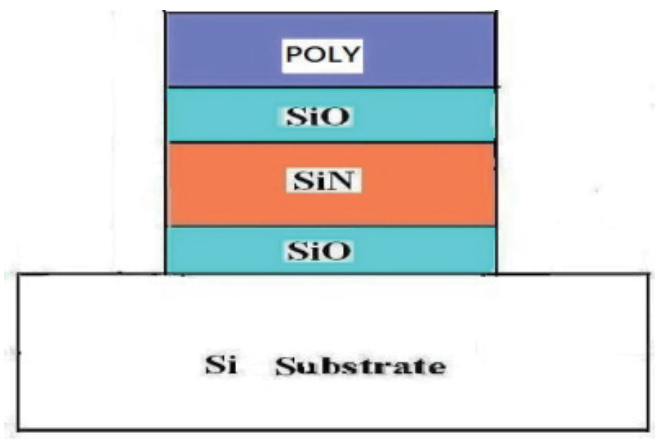

Fig. 1. (Color online) Cross-sectional view of a SONOS capacitor device.

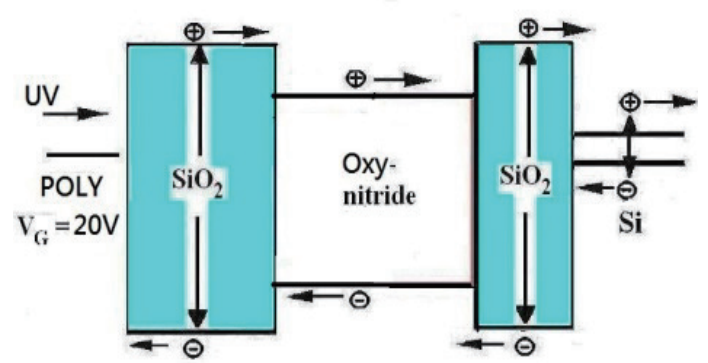

Fig. 2. (Color online) Charge generation and trapping in the O-SONOS capacitor after UV irradiation. 
fabricated on a p-type resistivity $15-25 \Omega-\mathrm{cm} \mathrm{Si}<100>$ substrate. We used thermal $\mathrm{SiO}_{2}$ for the tunneling oxide, chemical vapor deposition (CVD) nitride $\mathrm{Si}_{3} \mathrm{~N}_{4}$ for the trapping layer, CVD tetraethyl orthosilicate (TEOS) $\mathrm{SiO}_{2}$ for the blocking oxide of the gate dielectric, and lowpressure CVD (LPCVD) poly silicon for the gate material. The tunneling silicon oxide $\left(\mathrm{SiO}_{2}\right)$ was formed on the wafers using an advanced clustered vertical furnace. After the tunneling oxide was formed, silicon nitride $\left(\mathrm{Si}_{3} \mathrm{~N}_{4}\right)$ was deposited as the charge-trapping layer by LPCVD on the SONOS capacitor device. Two types of SONOS capacitor devices were prepared by adjusting the gas flow-rate ratio of $\mathrm{SiH}_{2} \mathrm{Cl}_{2}-\mathrm{NH}_{3}$ and $\mathrm{SiH}_{2} \mathrm{Cl}_{2}-\mathrm{N}_{2} \mathrm{O}$ during charge-trapping nitride film deposition: (1) SONOS capacitor with standard nitride $\left(\mathrm{SiH}_{2} \mathrm{Cl}_{2}: \mathrm{NH}_{3}=0.25: 1\right)$ as the charge-trapping layer (STD-SONOS), and (2) SONOS capacitor with oxy-nitride $\left(\mathrm{SiH}_{2} \mathrm{Cl}_{2}: \mathrm{NH}_{3}\right.$ $=2: 1$ and $\left.\mathrm{SiH}_{2} \mathrm{Cl}_{2}: \mathrm{N}_{2} \mathrm{O}=0.15: 1\right)$ as the charge-trapping layer (O-SONOS). The $\mathrm{SiO}_{2}-\mathrm{Si}_{3} \mathrm{~N}_{4}-$ $\mathrm{SiO}_{2}(\mathrm{ONO})$ gate stack consisted of a 1000-2000 $\AA$ silicon nitride and 50-150 $\AA$ bottom and top silicon oxides. The poly silicon (200-400 nm) was formed by LPCVD for the control gate. For comparison, the two types of SONOS capacitor devices had the same thicknesses of the tunneling oxide, trapping nitride, and blocking oxide layers. Figure 1 shows the cross-sectional view of the SONOS capacitor devices.

Before UV TD data writing, a negative gate bias stress (NGBS) of $-40 \mathrm{~V}$ was impinged on the SONOS capacitor devices first to "erase" the native charge in the ONO trapping layer of these SONOS devices before UV irradiation. During UV TD data writing, UV irradiation (UV LED, wavelength $400 \mathrm{~nm}$ ) together with PGBS was applied simultaneously on the SONOS capacitor devices. The various UV irradiation and PGBS conditions are listed in Table 1. After UV TD data writing, $V_{T}$ was measured at room temperature using a HP4156A parameter analyzer. The experimental results of gate capacitance applied at various gate voltages $\left(C_{G}-V_{G}\right)$ were obtained with a computer-controlled HP4284 parameter analyzer, and the $C_{G}-V_{G}$ curves were measured by sweeping $V_{G}$ at room temperature. Figure 2 shows the charge generation and trapping states of the gate dielectric in the O-SONOS capacitor device after UV irradiation.

\section{Results and Discussion}

\subsection{Radiation-induced $V_{T}$ shift in O-SONOS after UV irradiation}

Figure 3 shows the $C_{G}-V_{G}$ curve for a O-SONOS device before and after UV irradiation. The initial state of the O-SONOS capacitor device is in the erased state. NGBS $\left(V_{G}=-40\right.$ V) was impinged on the O-SONOS capacitor device first to "erase" the native charge in the ONO trapping layer. For UV TD data writing, UV irradiation together with PGBS $\left(V_{G}=20\right.$

Table 1

Symbol list for various UV TD and PGBS conditions on O-SONOS device.

\begin{tabular}{lcc}
\hline Symbol & UV TD $\left(\mathrm{mW} \cdot \mathrm{s} / \mathrm{cm}^{2}\right)$ & PGBS $V_{G}(\mathrm{~V})$ \\
\hline V0E0 & 0 & 0 \\
V0E100 & 100 & 0 \\
V20E0 & 0 & 20 \\
V20E100 & 100 & 20 \\
\hline
\end{tabular}




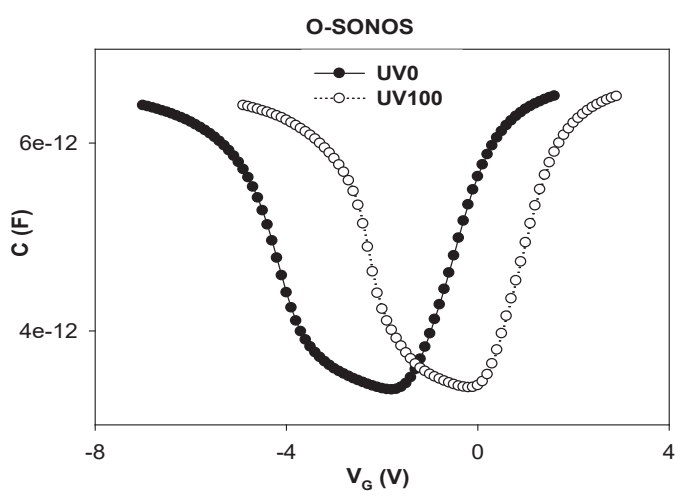

Fig. 3. $C_{G}-V_{G}$ curve for an O-SONOS device before UV irradiation and after UV TD $100 \mathrm{~mW} \cdot \mathrm{s} / \mathrm{cm}^{2}$ irradiation.

V) was impinged simultaneously on the O-SONOS capacitor devices. As shown in Fig. 3, $V_{T}$ is about $0 \mathrm{~V}$ for the O-SONOS capacitor device before UV irradiation, and it is about $2 \mathrm{~V}$ for the O-SONOS device after $100 \mathrm{~mW} \cdot \mathrm{s} / \mathrm{cm}^{2}$ TD UV irradiation under PGBS $\left(V_{G}=20 \mathrm{~V}\right)$. As illustrated in Fig. 3, the $C_{G}-V_{G}$ curve of O-SONOS shifted to the right after UV TD irradiation up to $100 \mathrm{~mW} \cdot \mathrm{s} / \mathrm{cm}^{2}$ under $20 \mathrm{~V}$ PGBS. This indicates that $100 \mathrm{~mW} \cdot \mathrm{s} / \mathrm{cm}^{2}$ TD UV irradiation induces an increase in $V_{T}$ (about $2 \mathrm{~V}$ ) for the O-SONOS capacitor under $20 \mathrm{~V}$ PGBS. This positive $V_{T}$ shift result is in agreement with previous studies. ${ }^{(1-3)}$

The positive $V_{T}$ shift is due to an increase in the net total negative trapped charges accumulated in the ONO gate dielectric layer after UV TD irradiation under $20 \mathrm{~V}$ PGBS. These radiation-induced positive $V_{T}$ shifts in the UV-irradiated O-SONOS device under $20 \mathrm{~V}$ PGBS result from electrons excited by UV photons, and then injected under $20 \mathrm{~V}$ PGBS over the Si$\mathrm{SiO}_{2}$ potential barrier into the trapping layer, and finally trapped in the nitride trapping layer of $\mathrm{ONO}^{(1-3)}$

UV TD irradiation and PGBS were applied on the O-SONOS capacitor device simultaneously for writing data by UV radiation. When the O-SONOS capacitor structures are subjected to UV TD irradiation, electrons from the silicon substrate can be excited by UV photons. These free carriers are swept by an electric field under PGBS over the $\mathrm{Si}_{-} \mathrm{SiO}_{2}$ potential barrier and injected into the ONO gate dielectric layer, and some of these carriers are captured by the charge trap centers in ONO trapping layer. The UV radiation writing induces a significant increase in $V_{T}$ for O-SONOS capacitor devices. It is considered that this $V_{T}$ change is mostly due to the significant increase in the amount of electron trapped charges in the gate dielectric ONO after UV TD data writing. It is considered that the amount of trapped electrons in the gate insulator due to UV TD data writing is greater than the amount of trapped holes in the gate dielectric ONO after UV TD data writing. The change in $V_{T}$ in this case can be correlated to the amount of trapped charges and the exposure TD of UV radiation as well. These trapped charges are accumulated in the gate dielectric layer, so the UV TD record cannot be destroyed or disturbed by the UV TD data write and read. For the UV TD data erase, the data in the SONOS capacitor devices can be erased to the original null state by the charge injection mechanism. 


\section{2 $V_{T}$ increase vs UV TD in O-SONOS capacitor after UV irradiation}

The $V_{T}$ increase is plotted against the UV irradiation TD for O-SONOS capacitors under 20 and $10 \mathrm{~V}$ PGBS as shown in Fig. 4. The $V_{T}$ increase as a function of UV TD for the O-SONOS capacitor device under $20 \mathrm{~V}$ PGBS is shown in Fig. 4. The increase in O-SONOS $V_{T}$ can be correlated to the increase in UV TD and the increase in the amount of negative trapped charges in the gate dielectric as well. However, $V_{T}$ increased more slowly when the UV TD is larger than $30 \mathrm{~mW} \cdot \mathrm{s} / \mathrm{cm}^{2}$. The experimental results of this study are in agreement with those of previous studies. ${ }^{(1-3)}$

The dependence of the $V_{T}$ shift on UV TD for O-SONOS was clearer under $20 \mathrm{~V}$ PGBS than under $10 \mathrm{~V}$ PGBS, as shown in Fig. 4. Under a higher PGBS, electrons are swept by a higher electric field and more electrons were captured by more charge trap centers of the ONO trapping layer.

Figure 5 shows the $V_{T}$ change vs PGBS for an O-SONOS capacitor device after various UV TD irradiations. The $V_{T}$ of O-SONOS capacitors was changed visibly under a high PGBS $\left(V_{G}\right.$ $=20 \mathrm{~V})$ even with low UV TD $\left(5 \mathrm{~mW} \cdot \mathrm{s} / \mathrm{cm}^{2}\right)$ irradiation, but the threshold voltage of O-SONOS capacitors was not changed significantly under low PGBS $\left(V_{G}=10 \mathrm{~V}\right)$ even with high UV TD (100 $\left.\mathrm{mW} \cdot \mathrm{s} / \mathrm{cm}^{2}\right)$ irradiation, and also changed negligibly with a high PGBS $\left(V_{G}=20 \mathrm{~V}\right)$ under zero UV TD irradiation $\left(0 \mathrm{~mW} \cdot \mathrm{s} / \mathrm{cm}^{2}\right)$. It is considered that the increase in threshold voltage is due to an increase in the amount of electron trapped charges in the gate dielectric ONO layer after UV TD irradiation together with PGBS.

The comparisons of $V_{T}$ increase in the two types of SONOS devices under various UV irradiation conditions are shown in Figs. 6(a) and 6(b). The symbol list for various UV and PGBS conditions on the SONOS device is shown in Table 1. As illustrated in Fig. 6(a), the change in the $V_{T}$ of SONOS was ignorable under only UV TD irradiation conditions (without PGBS), and also ignorable under only PGBS conditions (without UV TD irradiation). It is considered that both UV TD irradiation and PGBS should be applied to the O-SONOS capacitor

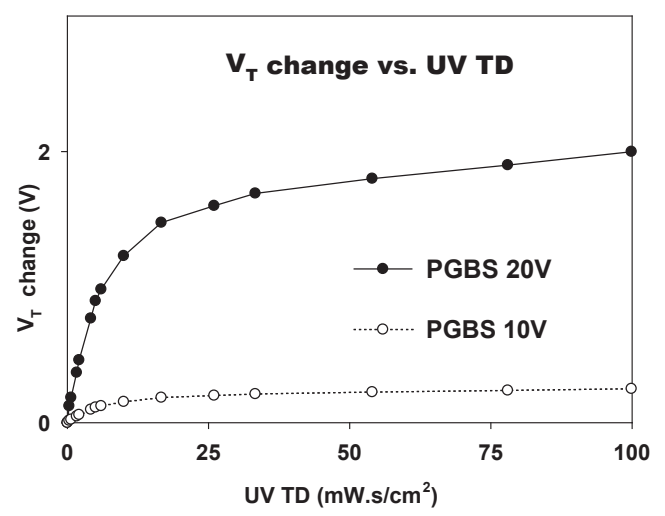

Fig. 4. Dependence of $V_{T}$ increase on UV irradiation TD for a O-SONOS under 20 and $10 \mathrm{~V}$ PGBS.

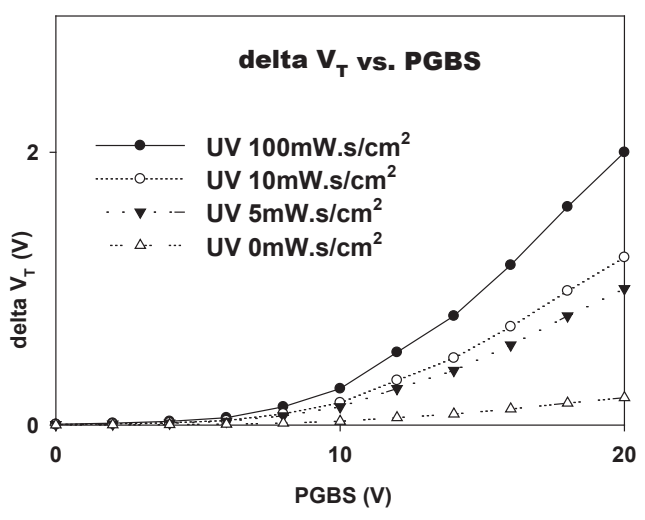

Fig. 5. Delta $V_{T}$ vs PGBS for an O-SONOS device after $\mathrm{UV} 100 \mathrm{~mW} \cdot \mathrm{s} / \mathrm{cm}^{2}$ TD irradiation, UV 10 $\mathrm{mW} \cdot \mathrm{s} / \mathrm{cm}^{2}$ TD irradiation, UV $5 \mathrm{~mW} \cdot \mathrm{s} / \mathrm{cm}^{2} \mathrm{TD}$ irradiation, and UV $0 \mathrm{~mW} \cdot \mathrm{s} / \mathrm{cm}^{2} \mathrm{TD}$ irradiation. 
device simultaneously for writing UV TD radiation data, and the significant increase in $V_{T}$ is due to a significant increase in the amount of electron trapped charges in the gate dielectric ONO layer after UV TD irradiation and PGBS simultaneously. As shown in Fig. 6(b), the UV TD radiation-induced $V_{T}$ increase of the O-SONOS device was 1.4 times larger than that of the STD-SONOS device after $100 \mathrm{~mW} \cdot \mathrm{s} / \mathrm{cm}^{2}$ UV TD under $20 \mathrm{~V}$ PGBS. The UV TD radiationinduced $V_{T}$ shift of the O-SONOS capacitor is more significant than that of the STD-SONOS capacitor as shown in Fig. 6(b), which results from the fact that the amount of UV TD radiationinduced charges trapped in the O-SONOS capacitor is greater than that in the STD-SONOS capacitor under PGBS. For comparison, the two types of SONOS capacitor devices had the same thicknesses of the tunneling oxide, trapping nitride, and blocking oxide layers.

\subsection{Measurement of gate leakage current}

The gate leakage current vs gate voltage $\left(I_{G}-V_{G}\right)$ curves for an O-SONOS capacitor device before and after $100 \mathrm{~mW} \cdot \mathrm{s} / \mathrm{cm}^{2}$ TD UV irradiation under $20 \mathrm{~V}$ PGBS are shown in Fig. 7. As illustrated in Fig. 7, the gate oxide leakage current of the O-SONOS capacitor device did not increase significantly after $100 \mathrm{~mW} \cdot \mathrm{s} / \mathrm{cm}^{2}$ TD UV irradiation under $20 \mathrm{~V}$ PGBS.

The gate currents of the two types of SONOS capacitor devices at $V_{G} 20 \mathrm{~V}$ after various UV irradiations are indicated in Figs. 8(a) and 8(b). As illustrated in the figures, the gate current of the O-SONOS capacitor device at $V_{G} 20 \mathrm{~V}$ did not increase significantly after various UV irradiations. The gate current of the STD-SONOS device at $V_{G} 20 \mathrm{~V}$ increased more significantly than that of the O-SONOS capacitor after $100 \mathrm{~mW} \cdot \mathrm{s} / \mathrm{cm}^{2}$ TD UV irradiation under 20 V PGBS.

\section{4 $V_{T}$ stability vs retention time}

The $V_{T}$ vs retention time for an O-SONOS capacitor device before and after $100 \mathrm{~mW} \cdot \mathrm{s} / \mathrm{cm}^{2}$ TD UV irradiation under $20 \mathrm{~V}$ PGBS is illustrated in Figs. 9(a) and 9(b), respectively. As illustrated in Fig. 9(a), the increase in $V_{T}$ with time for the pre-UV-irradiated O-SONOS

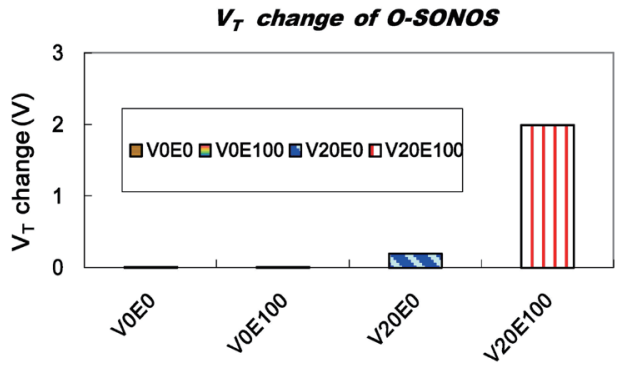

(a)

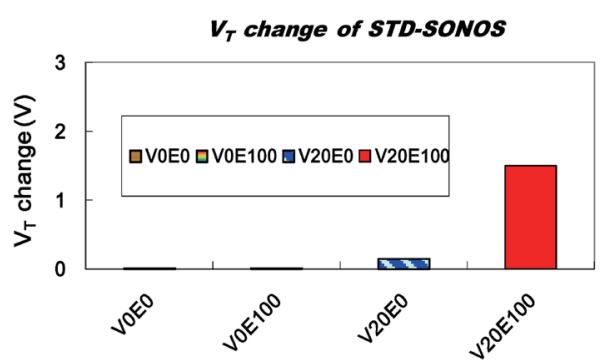

(b)

Fig. 6. (Color online) (a) $V_{T}$ change of O-SONOS devices after various UV irradiations and (b) $V_{T}$ change of STD-SONOS devices after various UV irradiations. 


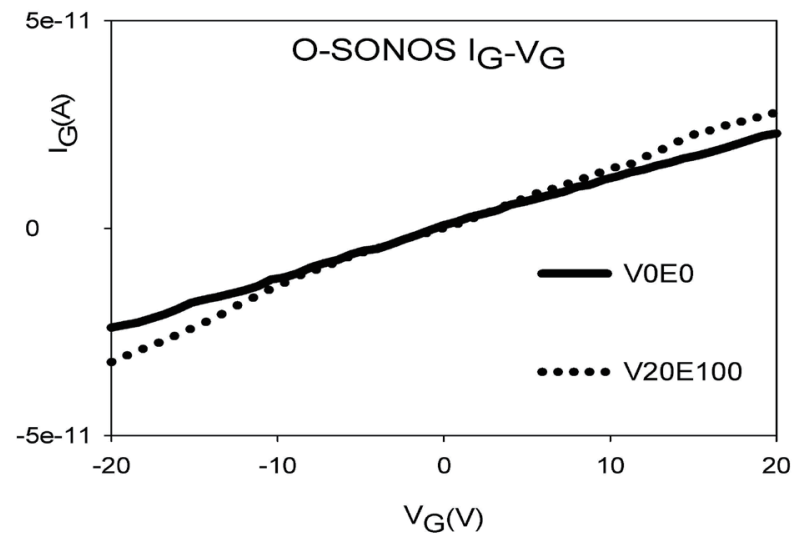

Fig. 7. Gate leakage current vs gate voltage $\left(I_{G}-V_{G}\right)$ curves for an O-SONOS device before UV irradiation and after UV TD $100 \mathrm{~mW} \cdot \mathrm{s} / \mathrm{cm}^{2}$ irradiation under $20 \mathrm{~V}$ PGBS.

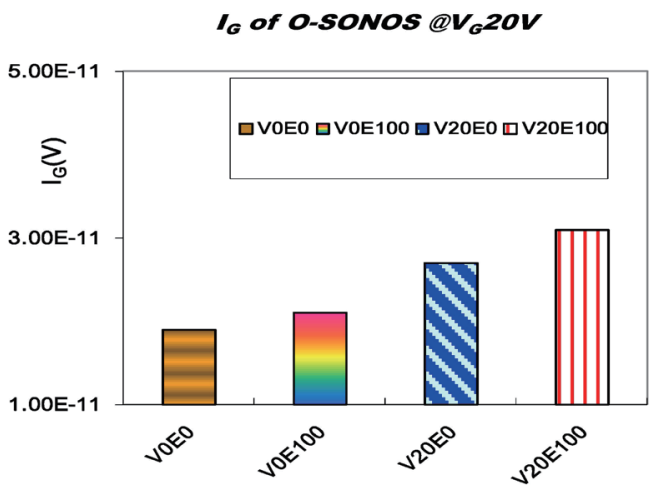

(a)

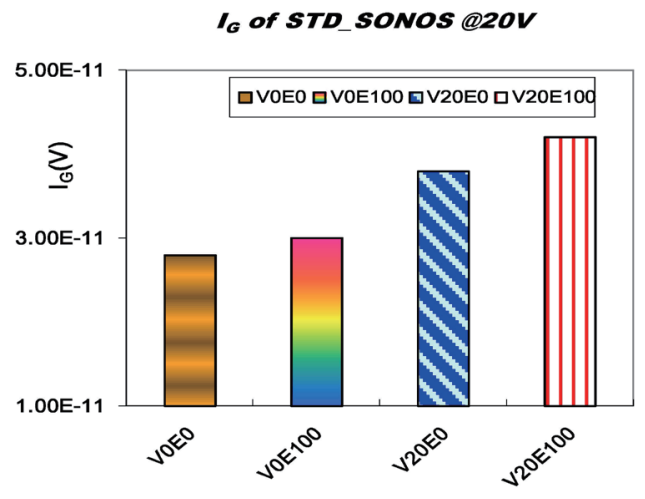

(b)

Fig. 8. (Color online) Gate currents of (a) O-SONOS devices at $V_{G}=20 \mathrm{~V}$ after various UV irradiations and (b) STD-SONOS devices at $V_{G}=20 \mathrm{~V}$ after various UV irradiations.

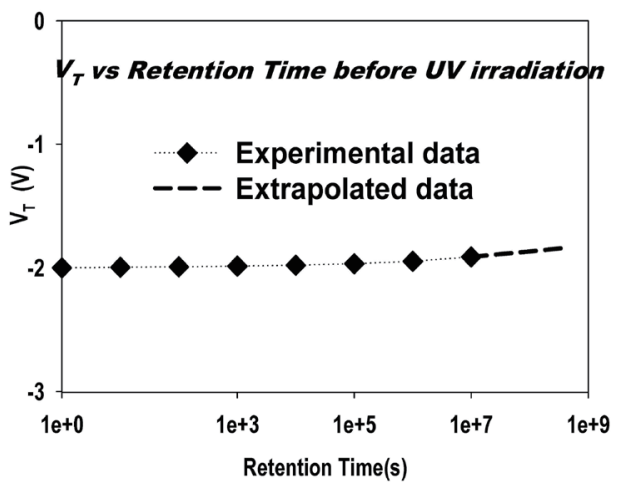

(a)

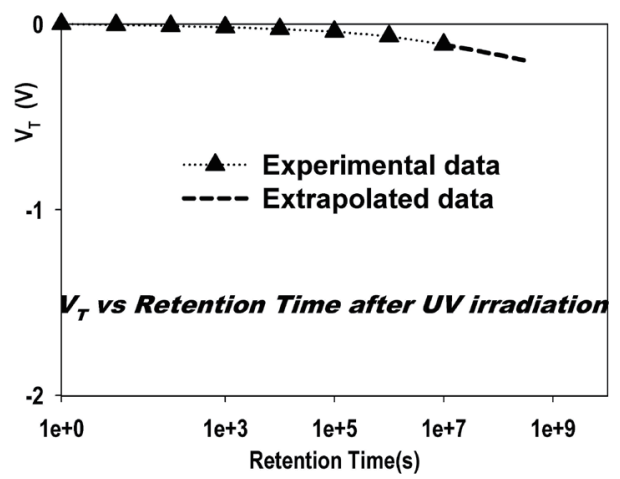

(b)

Fig. 9. $\quad V_{T}$ Vs retention time for an O-SONOS device: (a) before UV irradiation and (b) after UV TD $100 \mathrm{~mW} \cdot \mathrm{s} / \mathrm{cm}^{2}$ irradiation under $20 \mathrm{~V}$ PGBS. 
capacitor device is a result of negative charges naturally tunneling from the tunneling oxide into the oxy-nitride trapping layer of the O-SONOS device before UV irradiation. As shown in Fig. 9(b), the decrease in the $V_{T}$ with time for the post-UV-irradiated O-SONOS capacitor device is a result of UV-radiation-induced negative charges naturally tunneling out from the oxy-nitride trapping layer into the tunneling oxide. For the SONOS-type nonvolatile device, the electrons in the trapping layer find it difficult to escape to the control gate owing to the relatively larger barrier height of the thick $\mathrm{SiO}_{2}$ blocking oxide. As a result, negative charges accumulate permanently in the layers. The predicted change in $V_{T}$ after a 10-year retention was extrapolated from the experimental $V_{T^{-}} T$ curve after a 1-year retention, as shown in Figs. 9(a) and $9(\mathrm{~b}){ }^{(6,9,10)}$

Figures 10(a) and 10(b) show the comparison of the charge-retention reliability characteristics of the two types of SONOS capacitor devices before UV irradiation and after $100 \mathrm{~mW} \cdot \mathrm{s} / \mathrm{cm}^{2} \mathrm{TD}$ UV irradiation under $20 \mathrm{~V}$ PGBS. However, the O-SONOS demonstrated better UV-induced charge-retention reliability characteristics than the STD-SONOS. This result also agreed with the previous study of an O-SONOS device with an oxy-nitride charge-trapping layer. ${ }^{(5,9,10)}$ The $V_{T}$ loss from the preirradiated device as a function of annealing temperature was investigated to confirm the effect of the rich incorporation of $\mathrm{O}$ on the gate oxide leakage current and the charge-retention reliability characteristics of SONOS in previous studies. ${ }^{(5,9,10)}$ A much deeper charge trap energy level $\left(E_{T A}\right)$ was observed for an O-SONOS with an oxy-nitride trapping layer than for the STD-SONOS in previous studies. ${ }^{(5,9,10)}$ Therefore, the O-SONOS device with deeper charge traps in the oxy-nitride trapping layer showed better UV-induced chargeretention reliability characteristics than the STD-SONOS devices. The charge-retention loss of the nonvolatile O-SONOS capacitor after a 10 -year retention is below $10 \%$. The nonvolatile O-SONOS capacitor devices have very good reliability characteristics of $V_{T}$ retention, even for 10 years. The UV TD information can be permanently stored and accumulated in the nonvolatile O-SONOS capacitor devices.

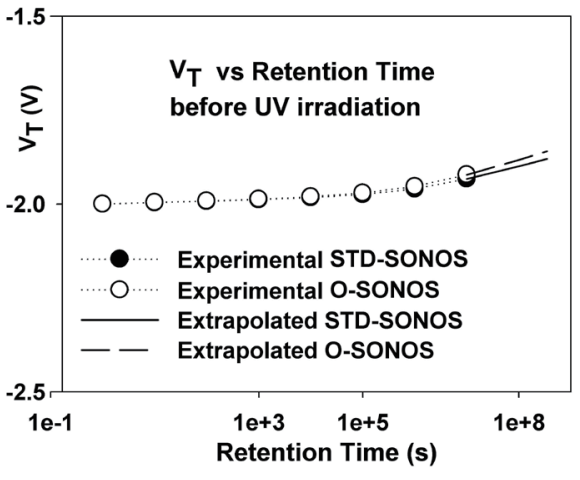

(a)

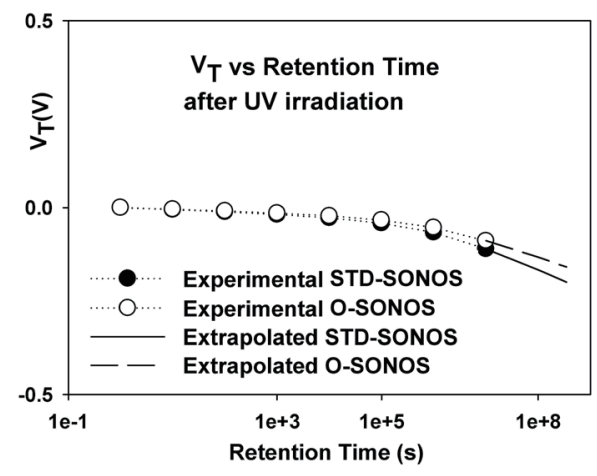

(b)

Fig. 10. Comparison of $V_{T}$ vs retention time for O-SONOS and STD-SONOS devices: (a) before UV irradiation and (b) after $100 \mathrm{~mW} \cdot \mathrm{s} / \mathrm{cm}^{2}$ TD UV irradiation under $20 \mathrm{~V}$ PGBS. 


\section{Conclusions}

As shown in the experiment data, the $V_{T}$ increase of the O-SONOS capacitor was nearly $2 \mathrm{~V}$, and was 1.4 times larger than that of the STD-SONOS capacitor after $100 \mathrm{~mW} \cdot \mathrm{s} / \mathrm{cm}^{2}$ TD UV irradiation under $20 \mathrm{~V}$ PGBS. The UV-irradiation-induced change in $V_{T}$ for the O-SONOS capacitor also has a strong correlation to UV TD up to $100 \mathrm{~mW} \cdot \mathrm{s} / \mathrm{cm}^{2}$ irradiation. However, the $V_{T}$ of the O-SONOS capacitor was not changed clearly with $100 \mathrm{~mW} \cdot \mathrm{s} / \mathrm{cm}^{2} \mathrm{TD}$ UV irradiation only (without PGBS) or with $20 \mathrm{~V}$ PGBS only (without UV TD irradiation). Moreover, the O-SONOS devices with deeper charge traps in the oxy-nitride trapping layer showed better UV-induced charge-retention reliability characteristics than the STD-SONOS devices. The $100 \mathrm{~mW} \cdot \mathrm{s} / \mathrm{cm}^{2} \mathrm{UV}$-induced charge-retention loss of the nonvolatile O-SONOS capacitor after a 10 -year retention is below $10 \%$. The results obtained in this study have demonstrated that the UV TD information can be permanently stored and accumulated in nonvolatile O-SONOS capacitor devices.

\section{Acknowledgments}

The authors thank the National Nano Device Laboratories (NDL), National Tsing Hua University (NTHU), and National Chiao Tung University (NCTU) for providing the instruments needed for wafer fabrication and testing. This study was funded in part by the National Science Council (NSC).

\section{References}

1 W. C. Hsieh, H. T. Lee, F. C. Jong, and S. C. Wu: 2013 Int. Conf. Advanced Infocomm Technology (IEEE, 2013) 163.

2 Y. Roizin and M. Gutman: Proc. 8th IEEE Int. Symp. IEEE Plasma- and Process-Induced Damage (IEEE, 2003) 61.

3 A. Abraham, N. Nicola, N. Diana, and M. Curiel: Key Eng. Mater. 605 (2014) 380.

4 W. C. Hsieh, H. T. Lee, F. C. Jong, and S. C. Wu: Sens. Mater. 5 (2016) 577.

5 W. C. Hsieh, H. T. Lee, F. C. Jong, and S. C. Wu: Sens. Mater. 9 (2016) 1023.

6 W. C. Hsieh, H. T. Lee, F. C. Jong, and S. C. Wu: Sens. Mater. 7 (2017) 969.

7 T. R. Oldham and F. B. McLean: IEEE Trans. Nucl. Sci. 50 (2003) 483.

8 Y. Cheng, M. Ding, X. Wu, X. Liu, and K. Wu: 2013 Int. Conf. Solid Dielectrics (IEEE, 2013) 764.

9 J. P. Colonna, E. Nowak, and G. Molas: Proc. 27th Int. Conf. Microelectronics (MIEL) (Nis, 2010) 1.

10 C. Sandhya, A. B. Oak, N. Chattar, A. S. Joshi, and U. Ganguly: IEEE Trans. Electron Devices 56 (2009) 3123 . 